\title{
Practical synthesis of polymethylated flavones: nobiletin and its desmethyl derivatives
}

Tomohiro Asakawa, ${ }^{\S, \$}$ Hiroto Sagara, ${ }^{\S}$ Masaki Kanakogi, ${ }^{\S}$ Aiki Hiza, ${ }^{\S}$ Yuta Tsukaguchi, ${ }^{\S}$ Takahiro Ogawa, ${ }^{\S}$ Miho Nakayama, ${ }^{\S}$ Hitoshi Ouchi, ${ }^{\S}$ Makoto Inai, ${ }^{\S} \quad$ Toshiyuki Kan ${ }^{\S}$ *

${ }^{\S}$ School of Pharmaceutical Sciences, University of Shizuoka, 52-1 Yada, Suruga-ku, Shizuoka 4228526, Japan,

¥Tokai University Institute of Innovative Science and Technology, 4-1-1, Kitakaname, Hiratsukacity, Kanagawa 259-1292, Japan 


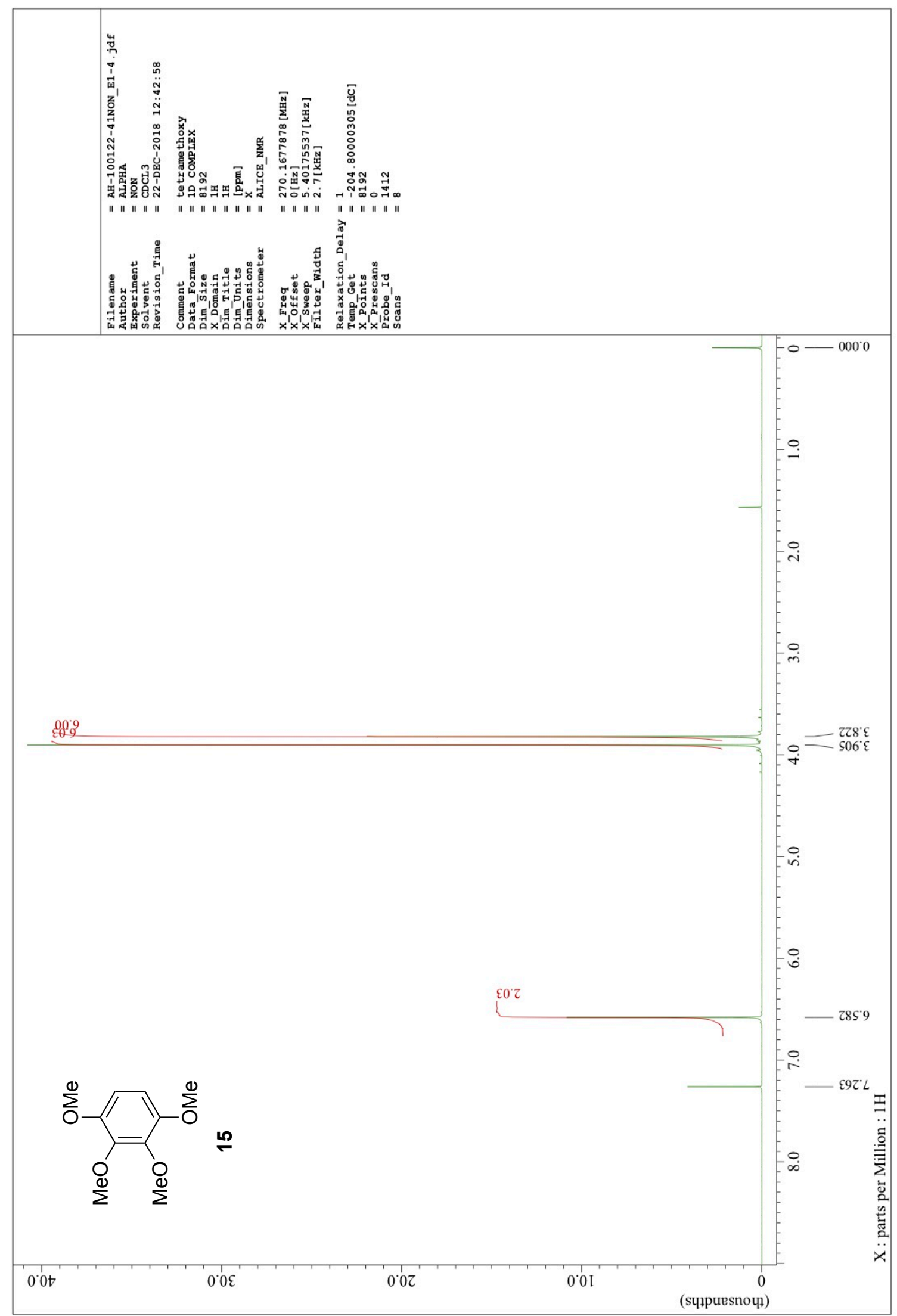




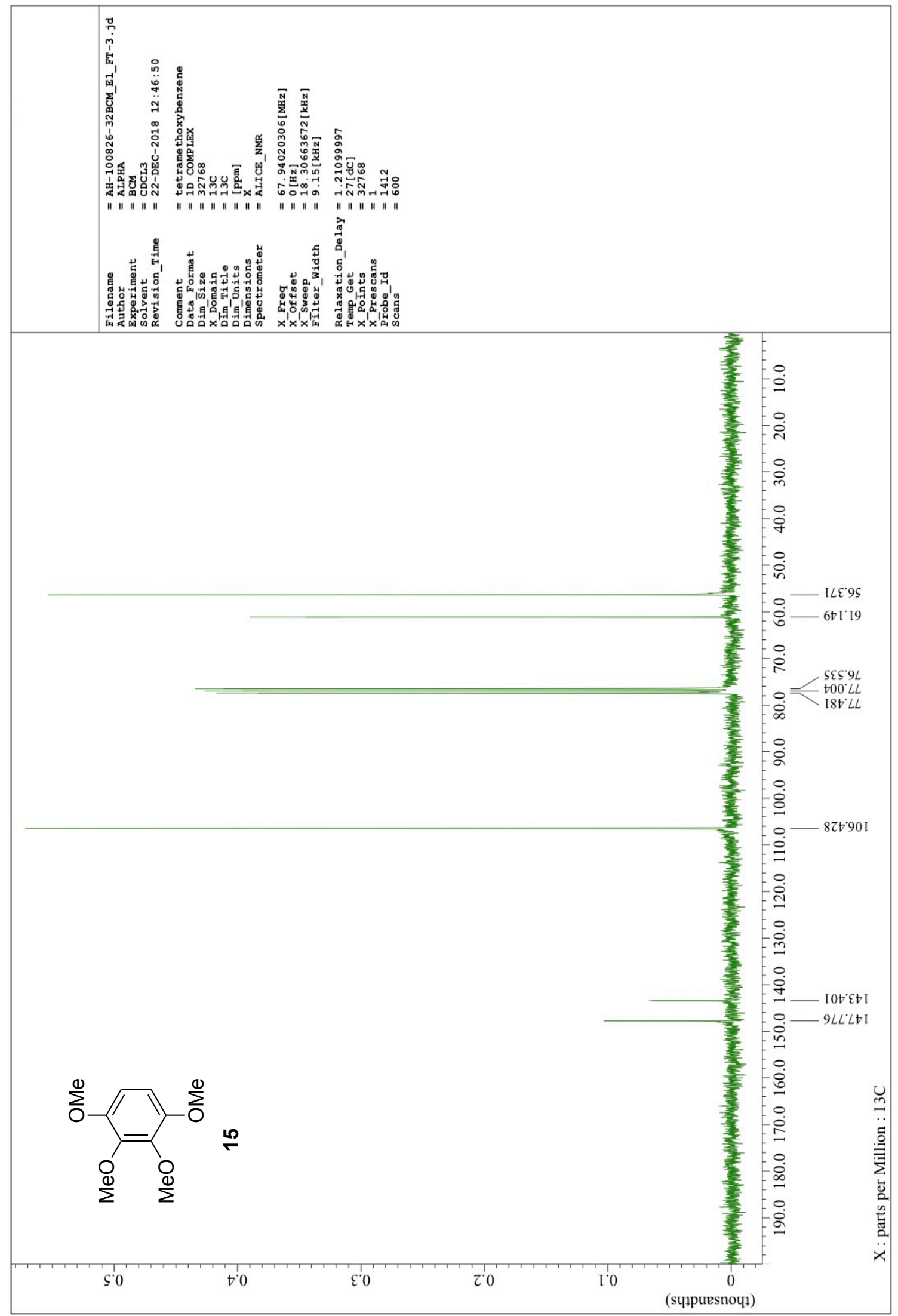




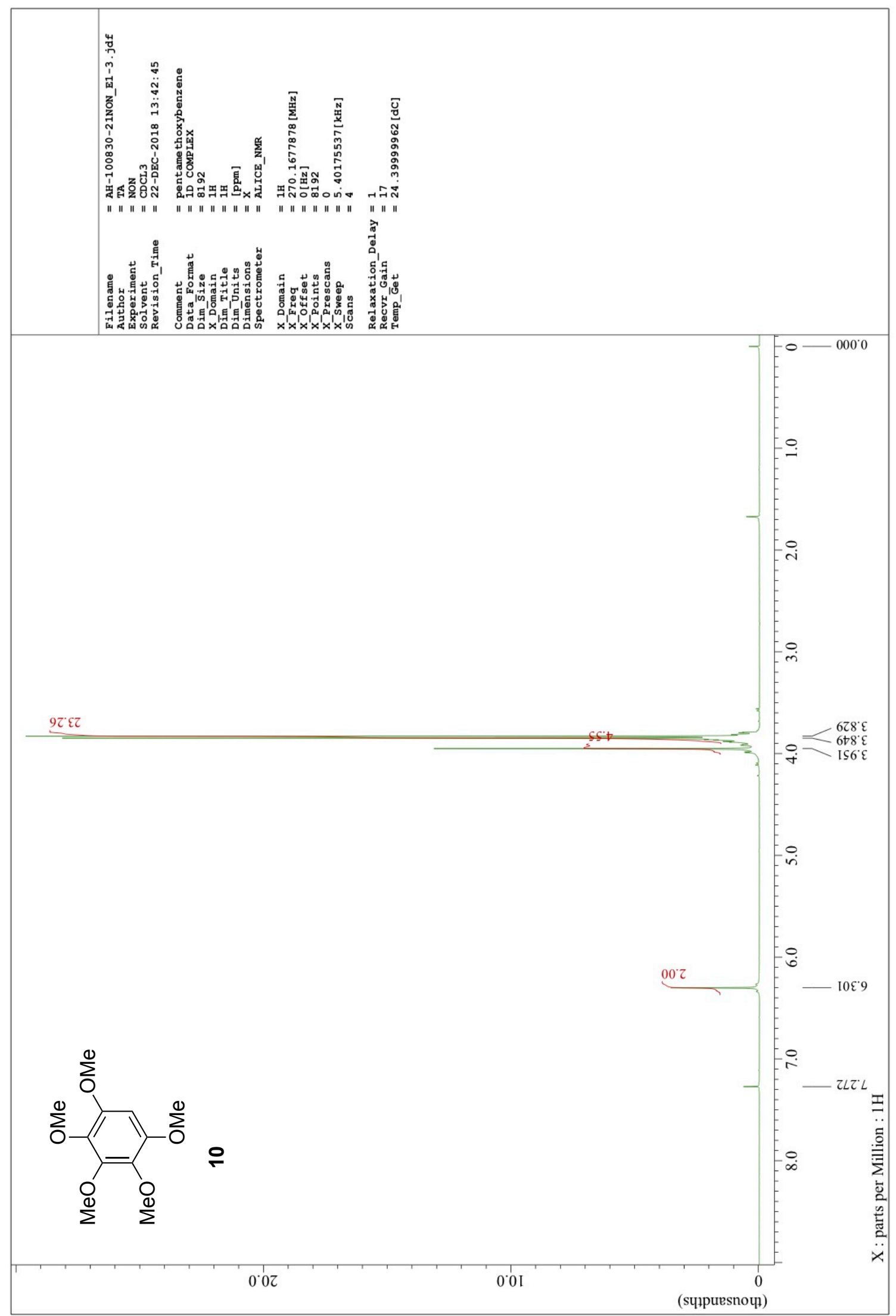




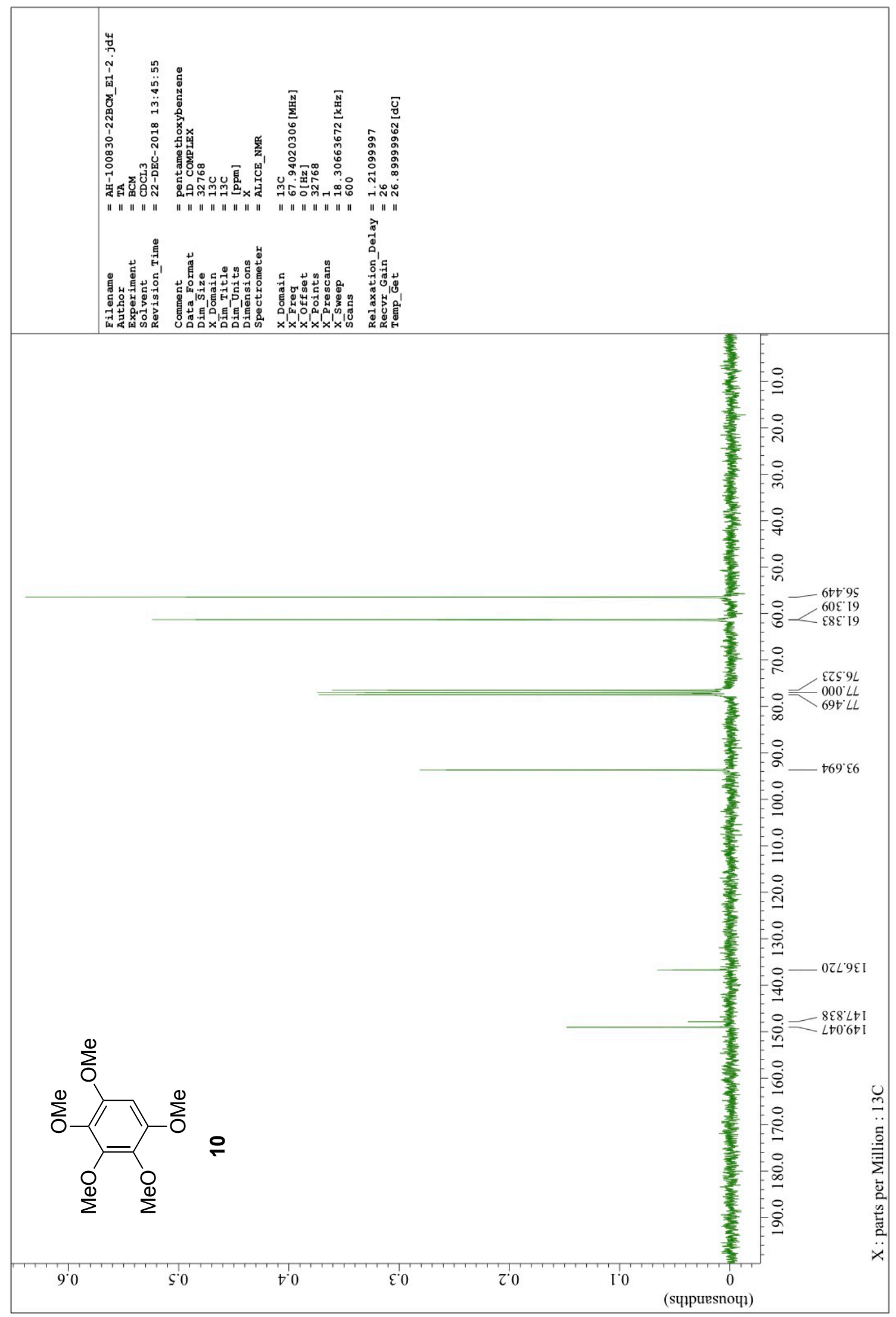




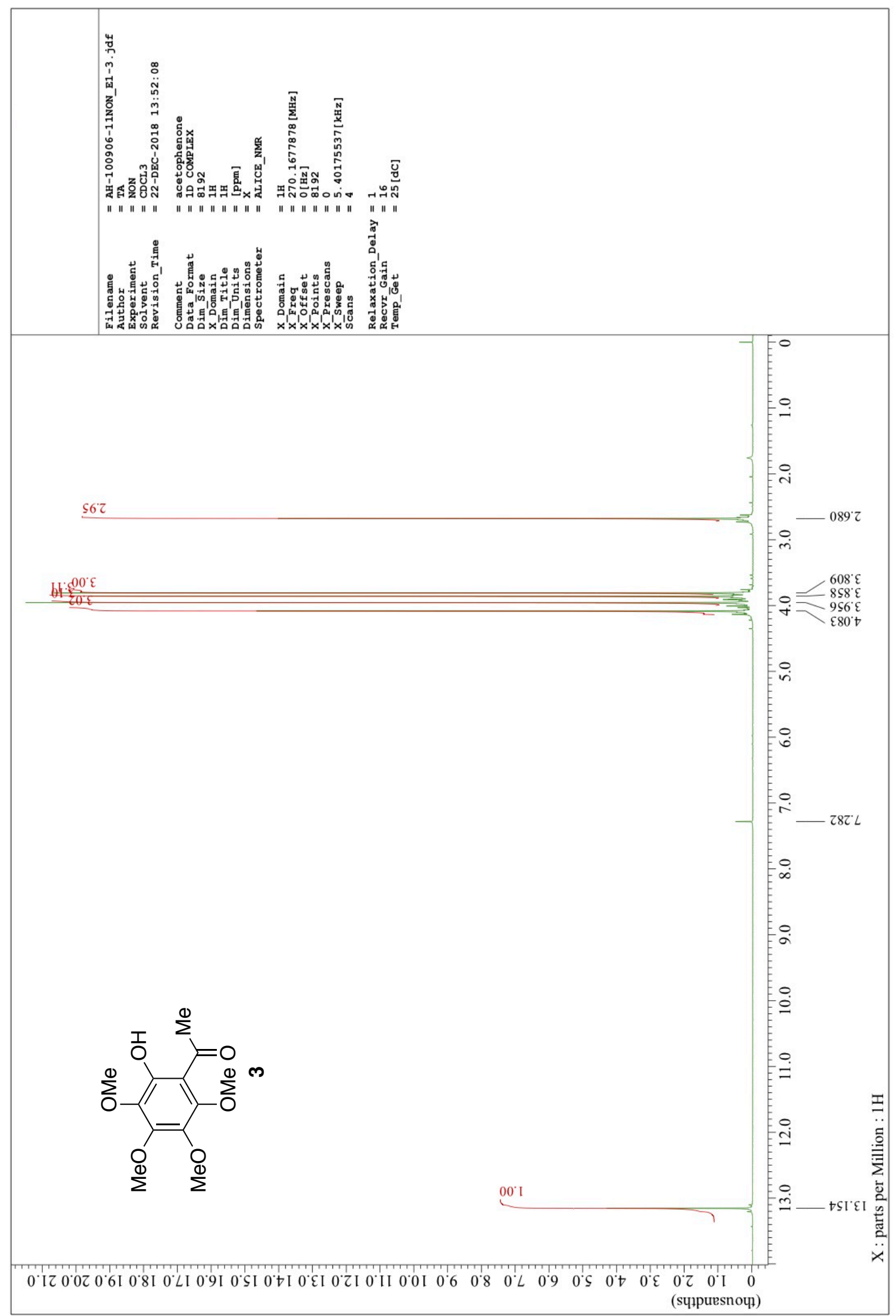




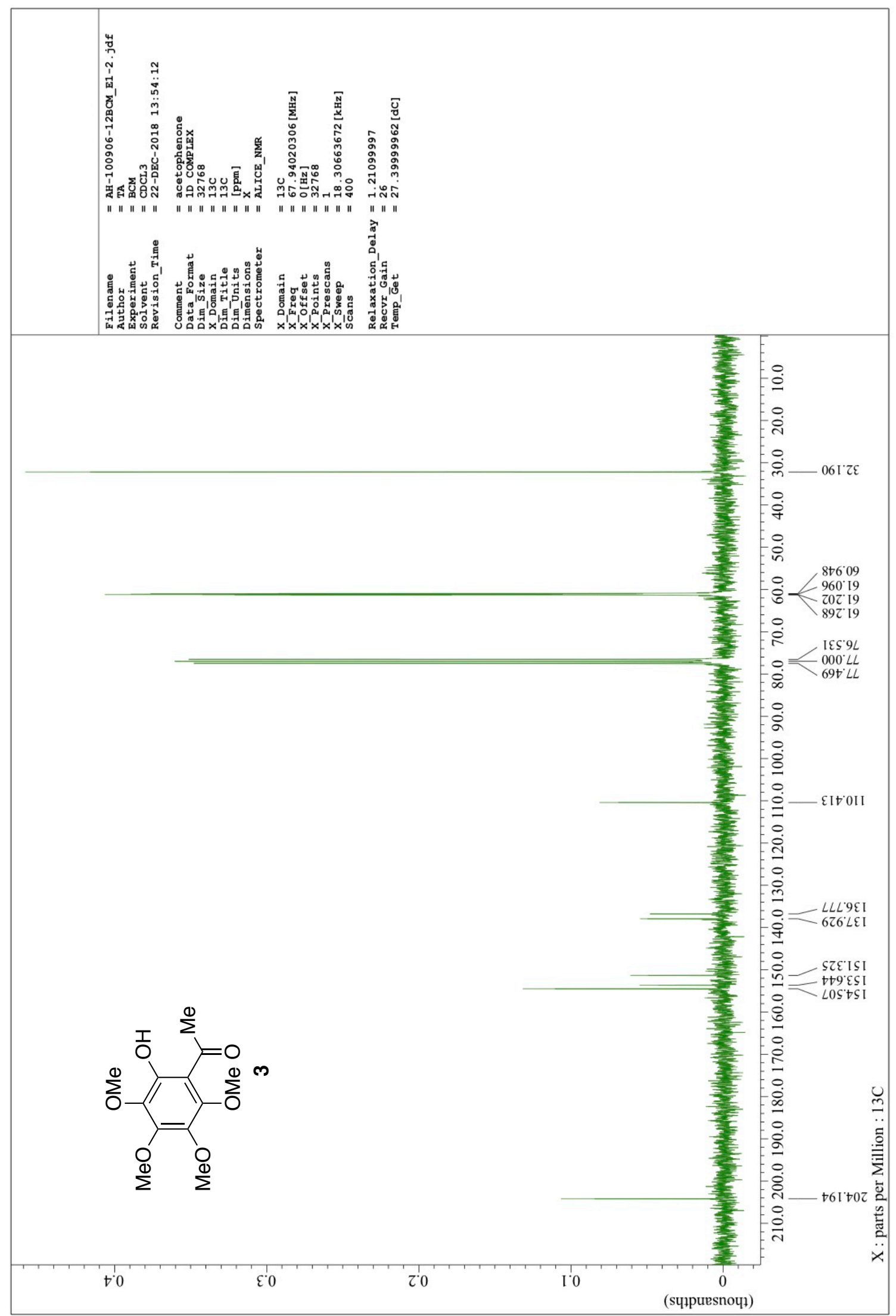




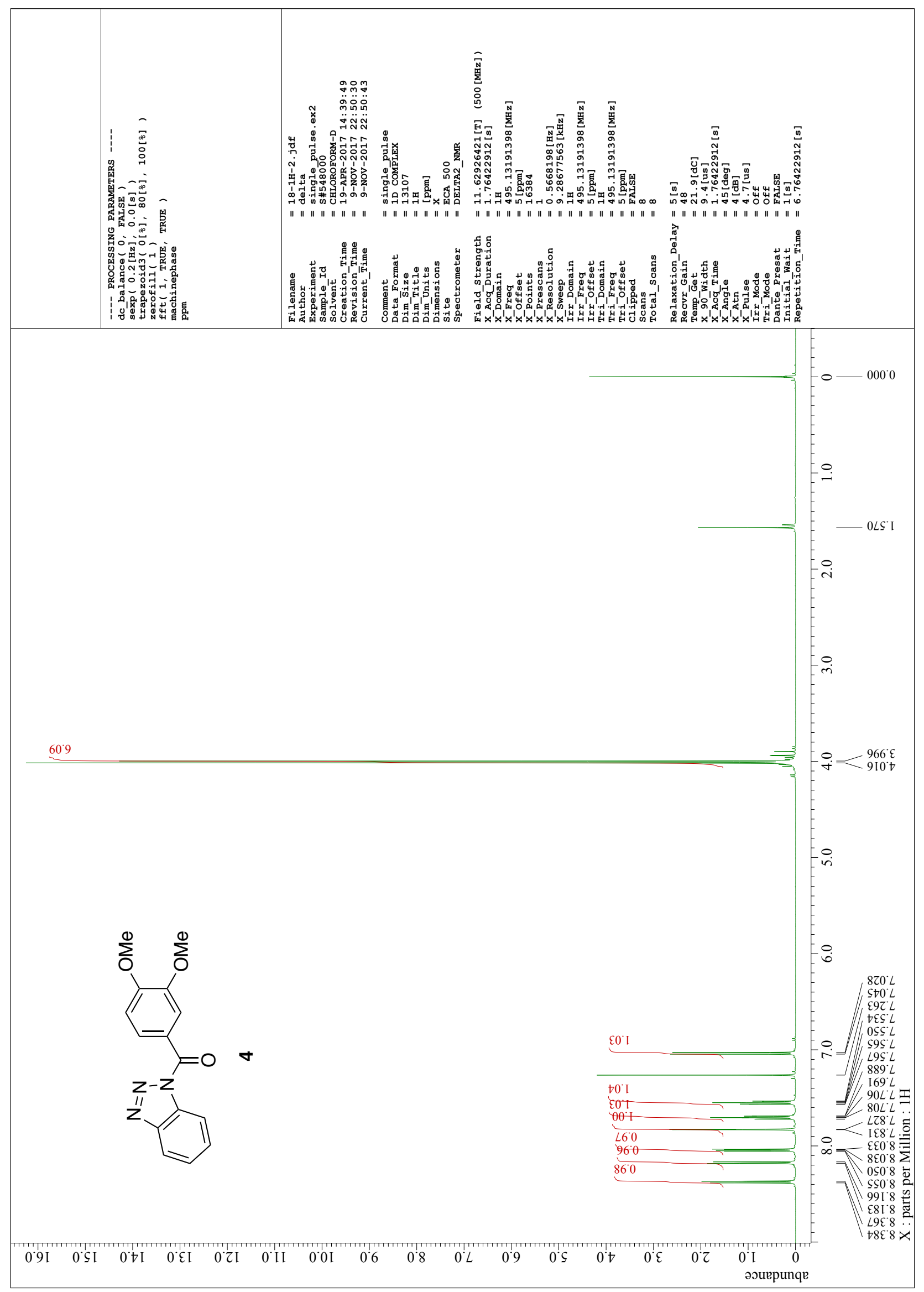




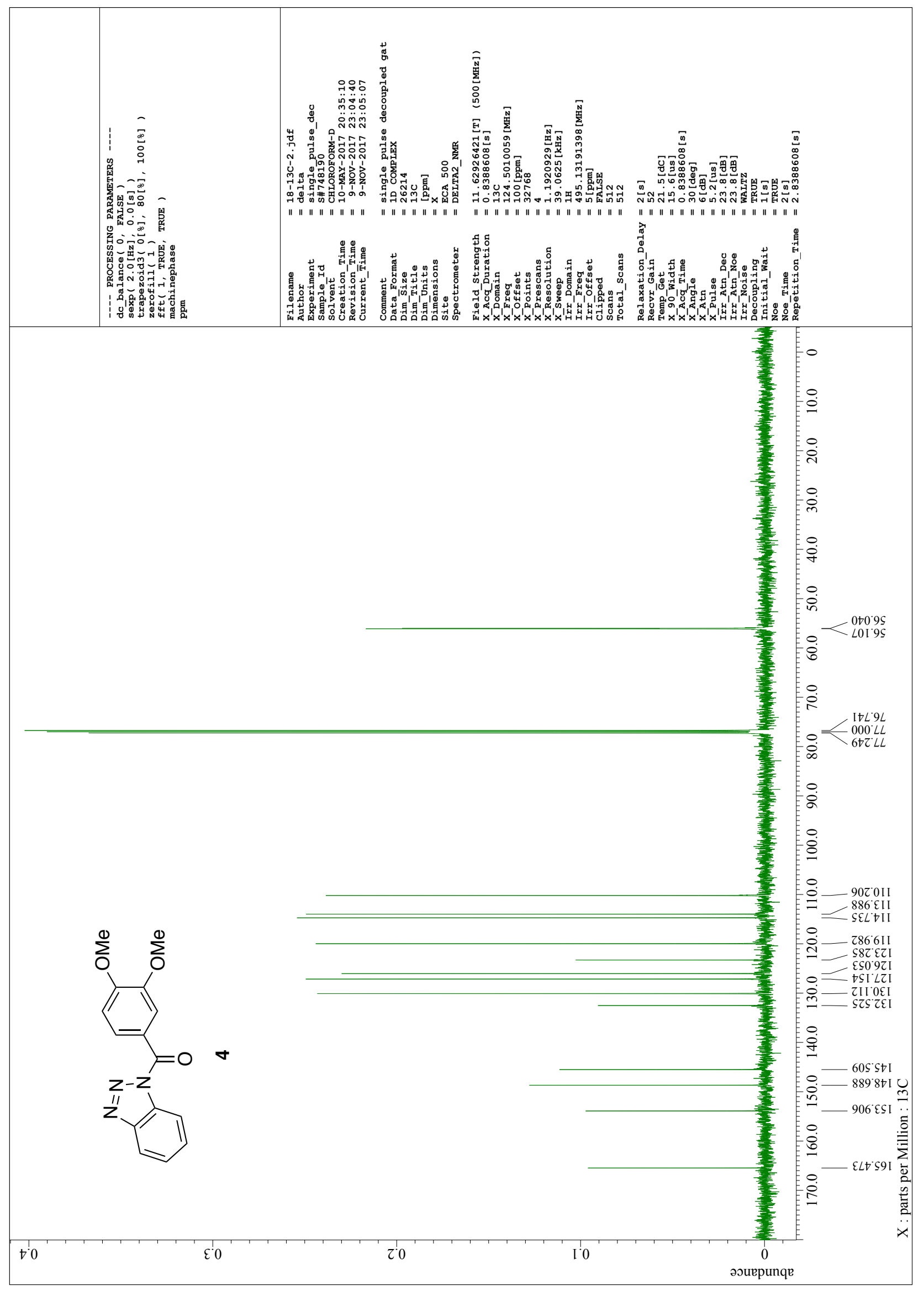




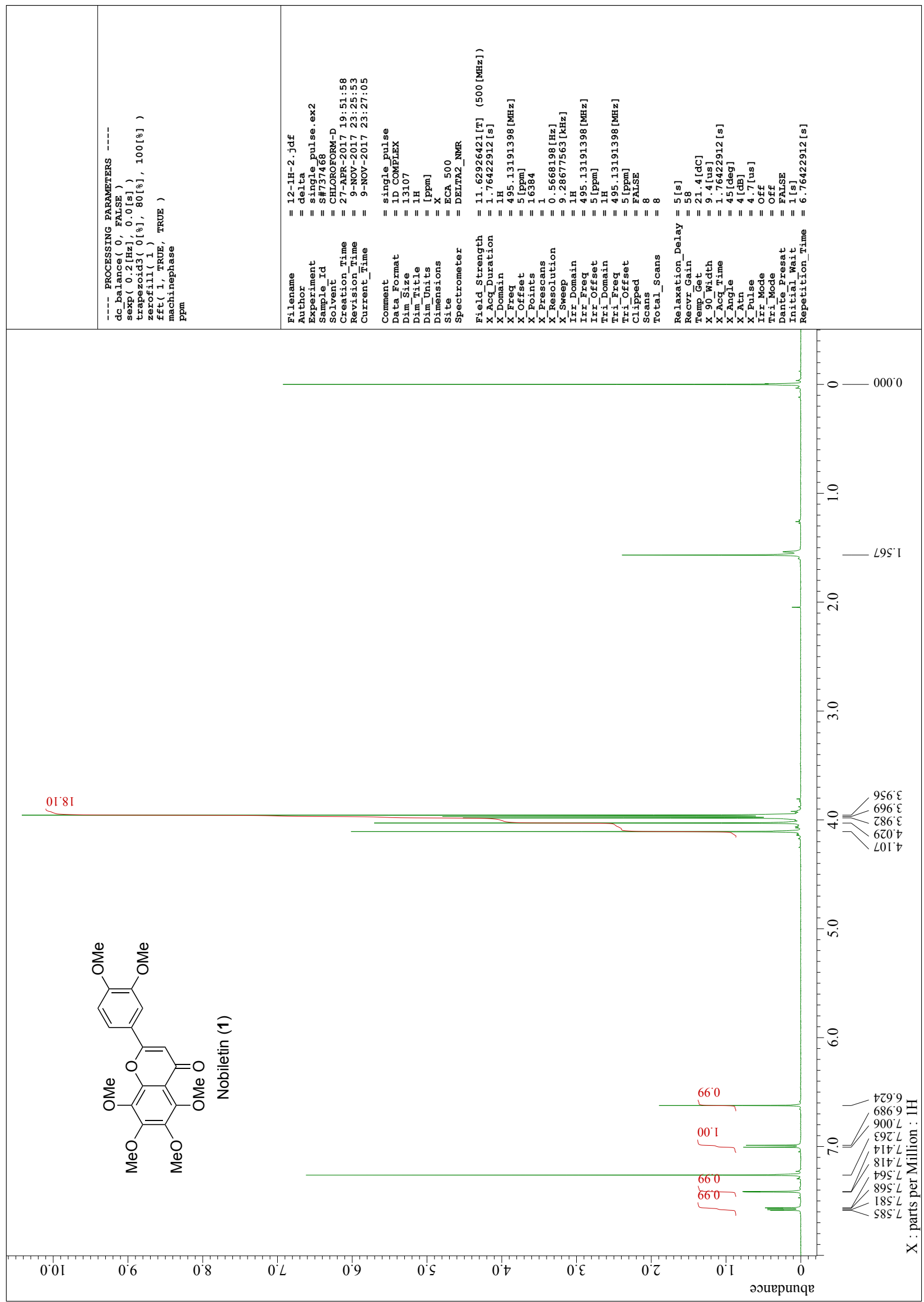




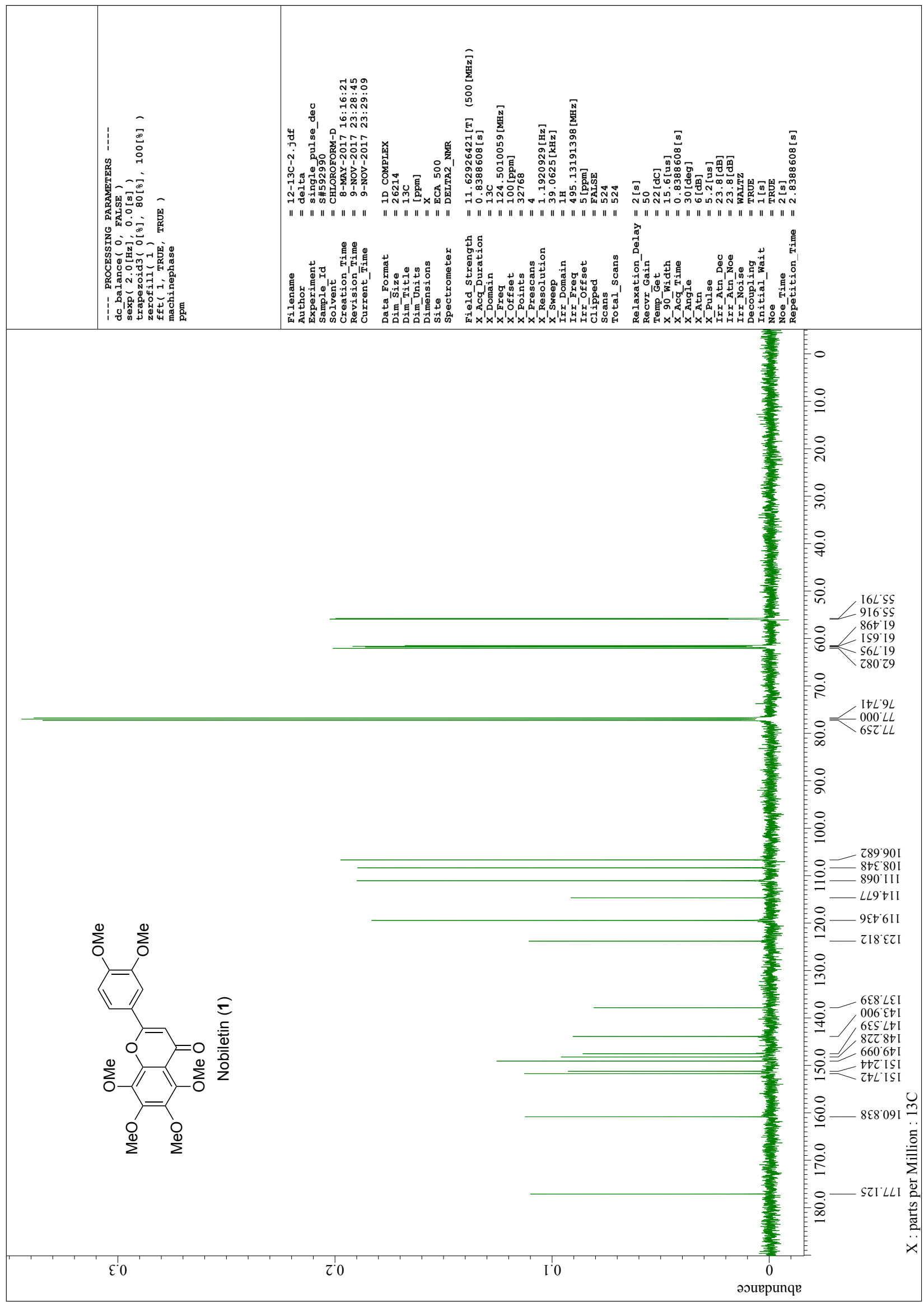




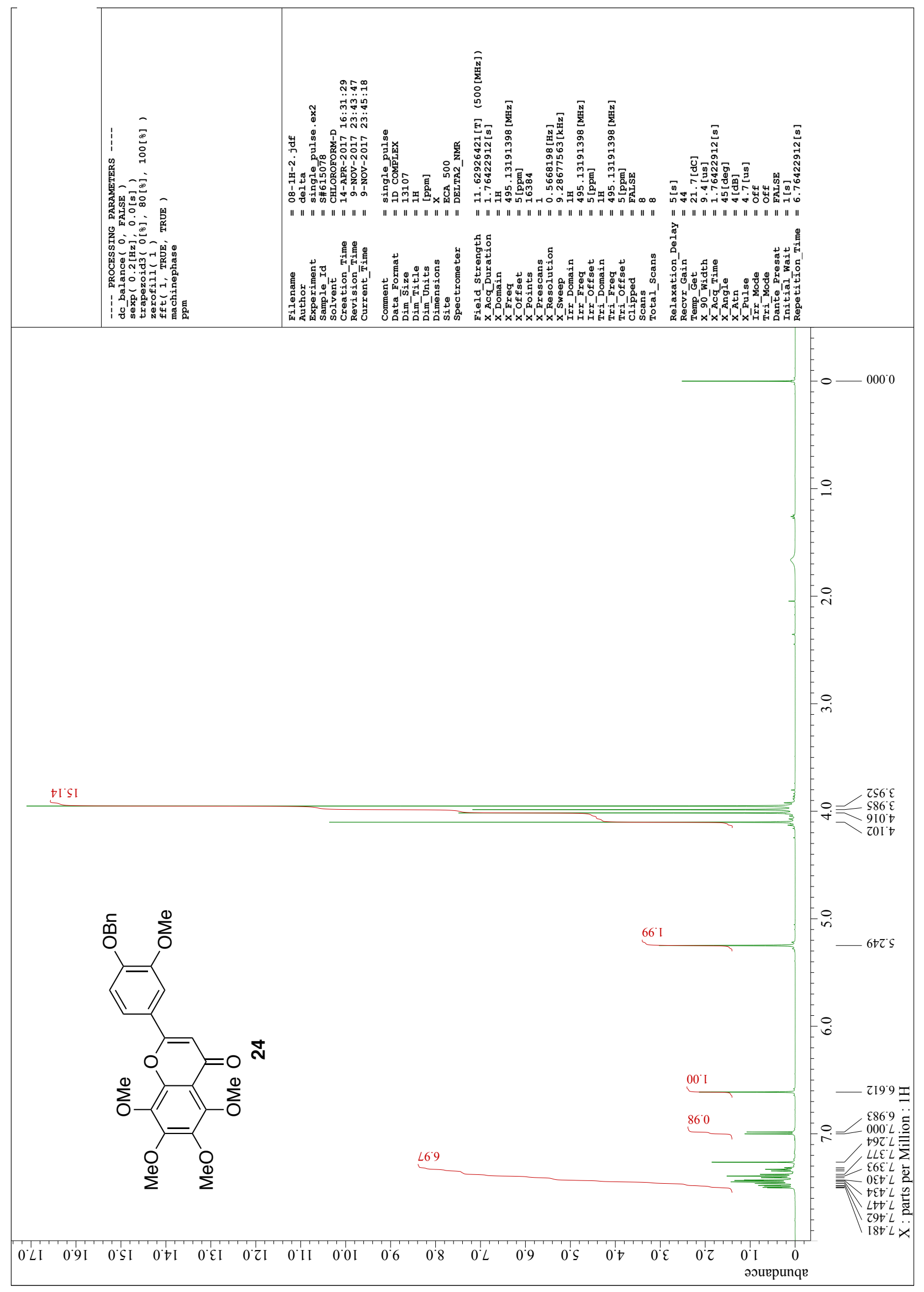




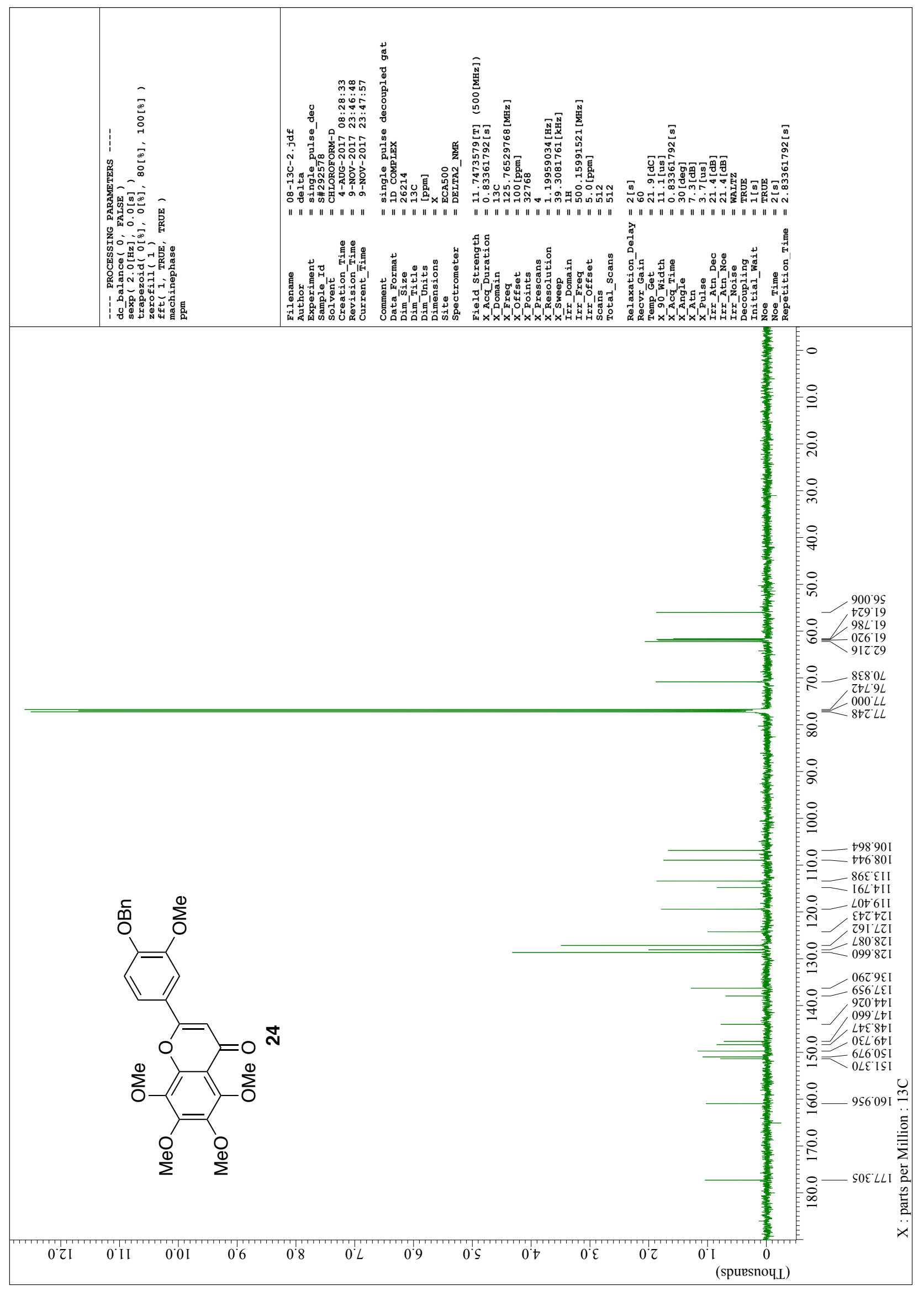




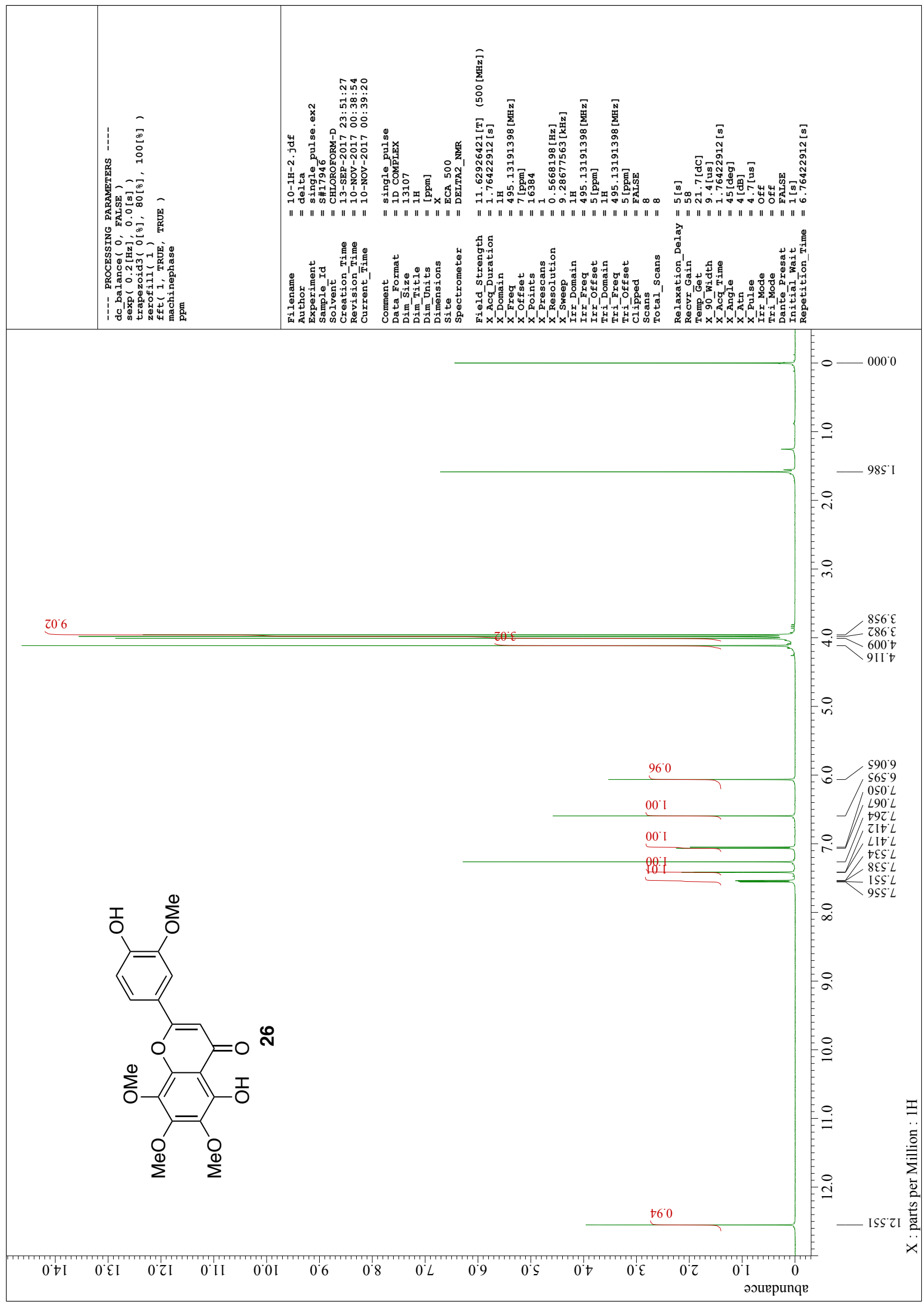




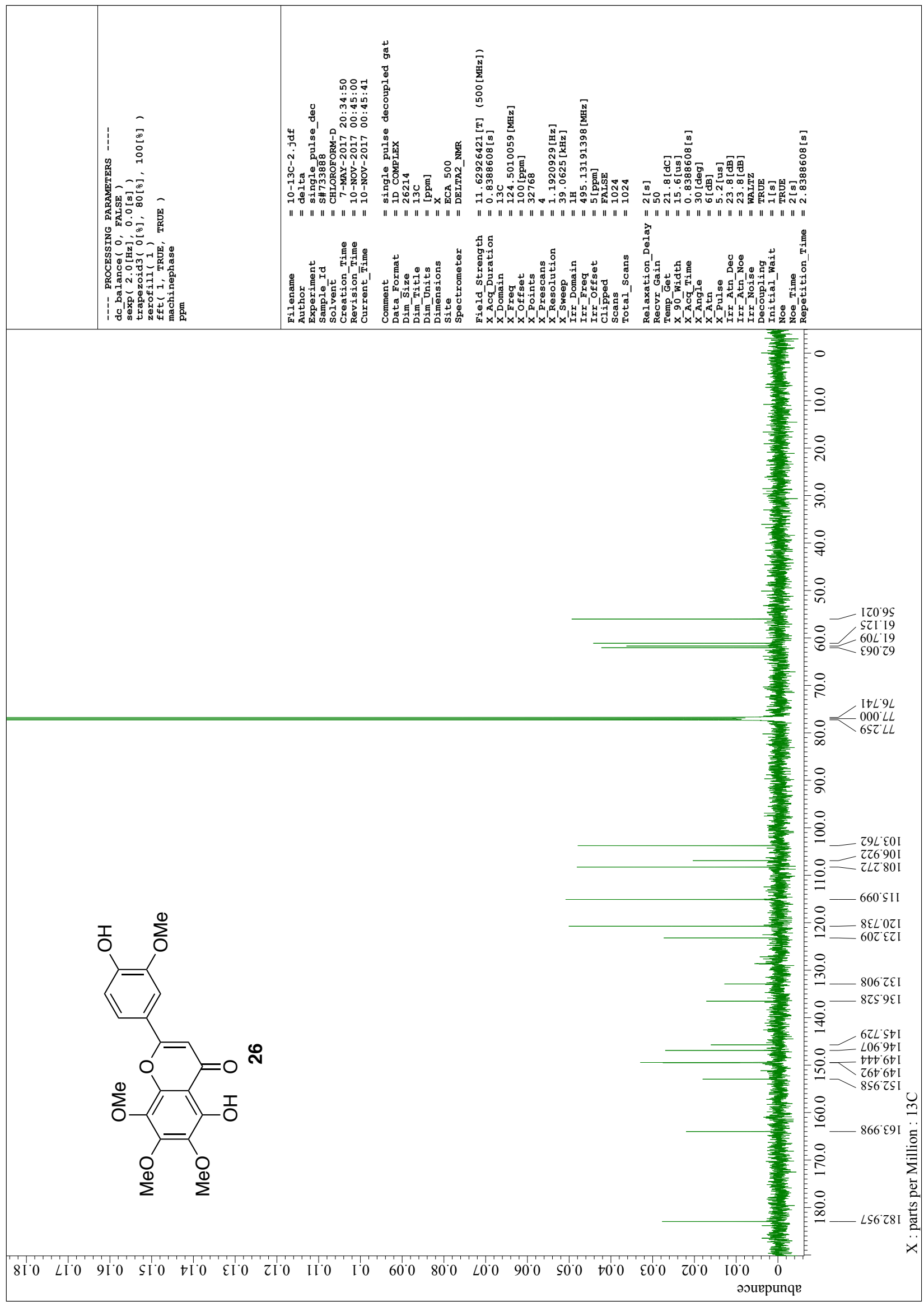




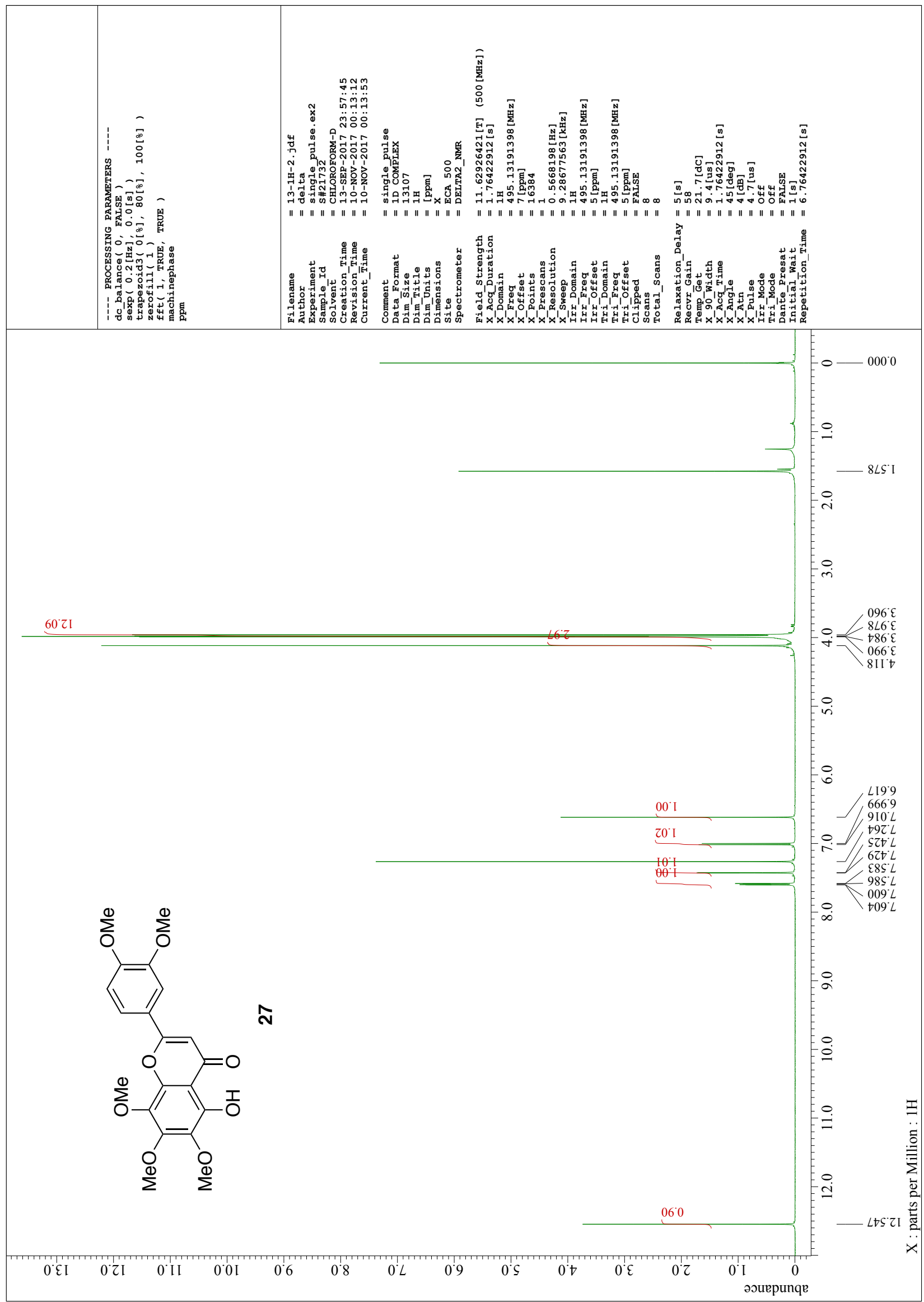




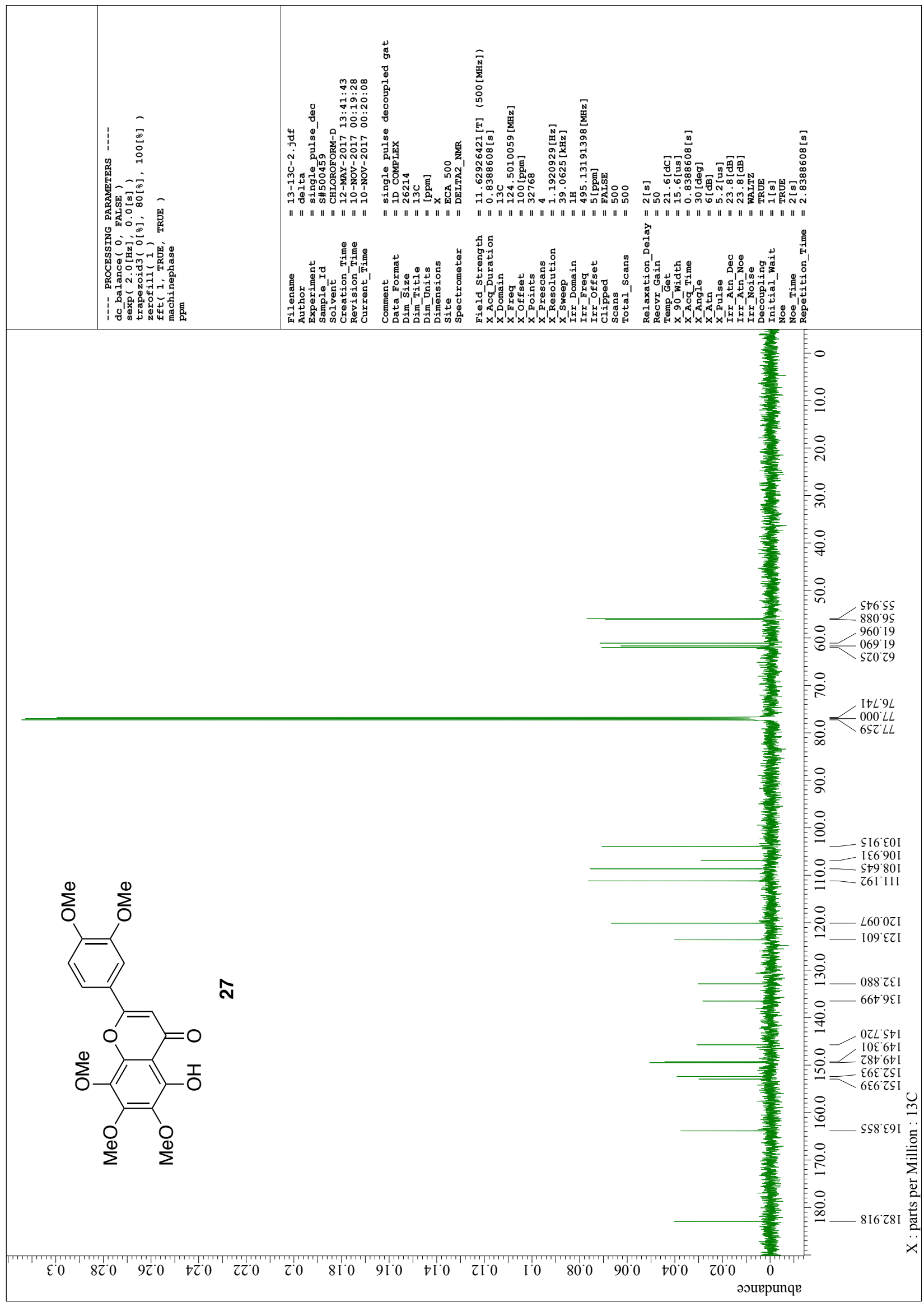




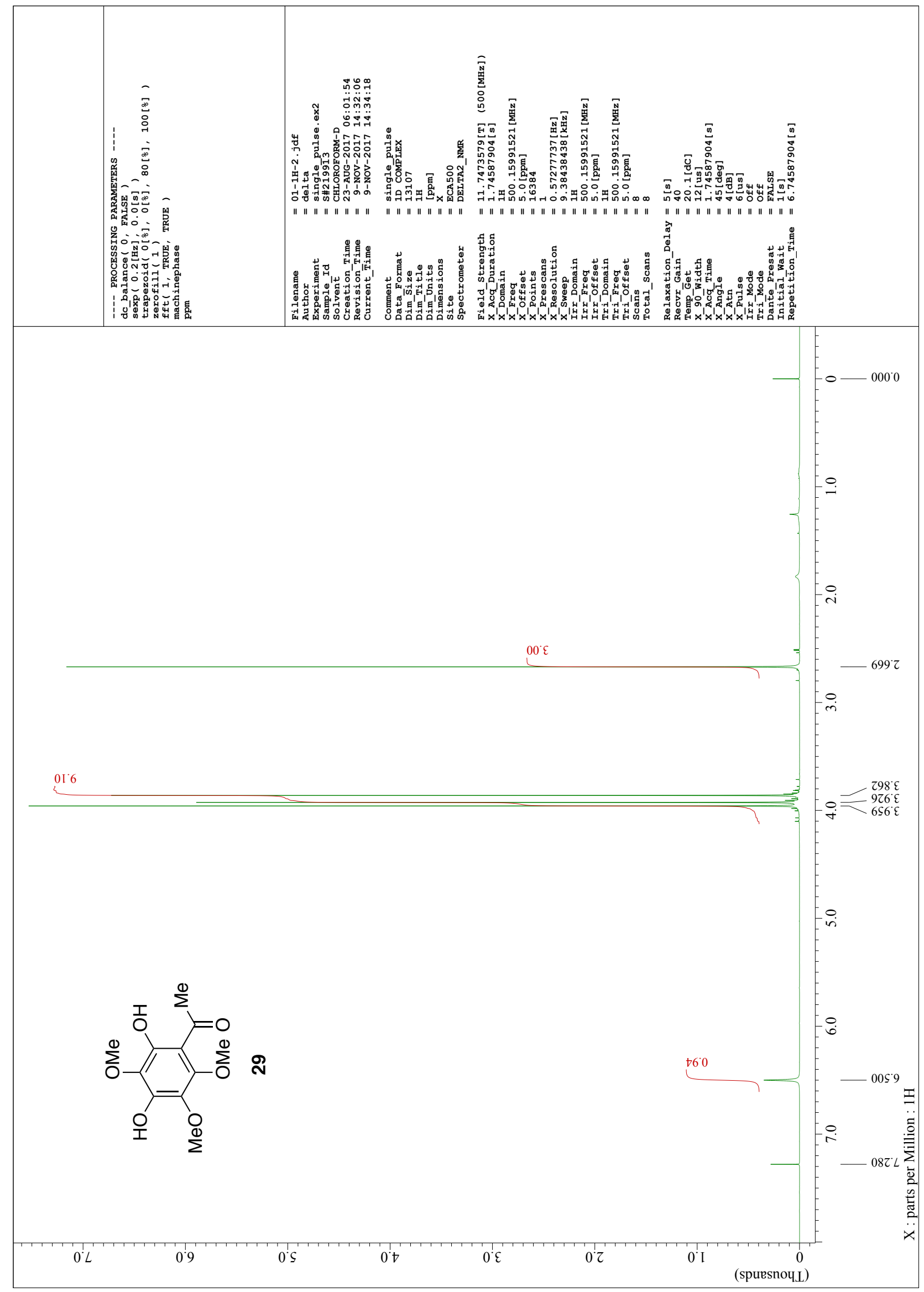




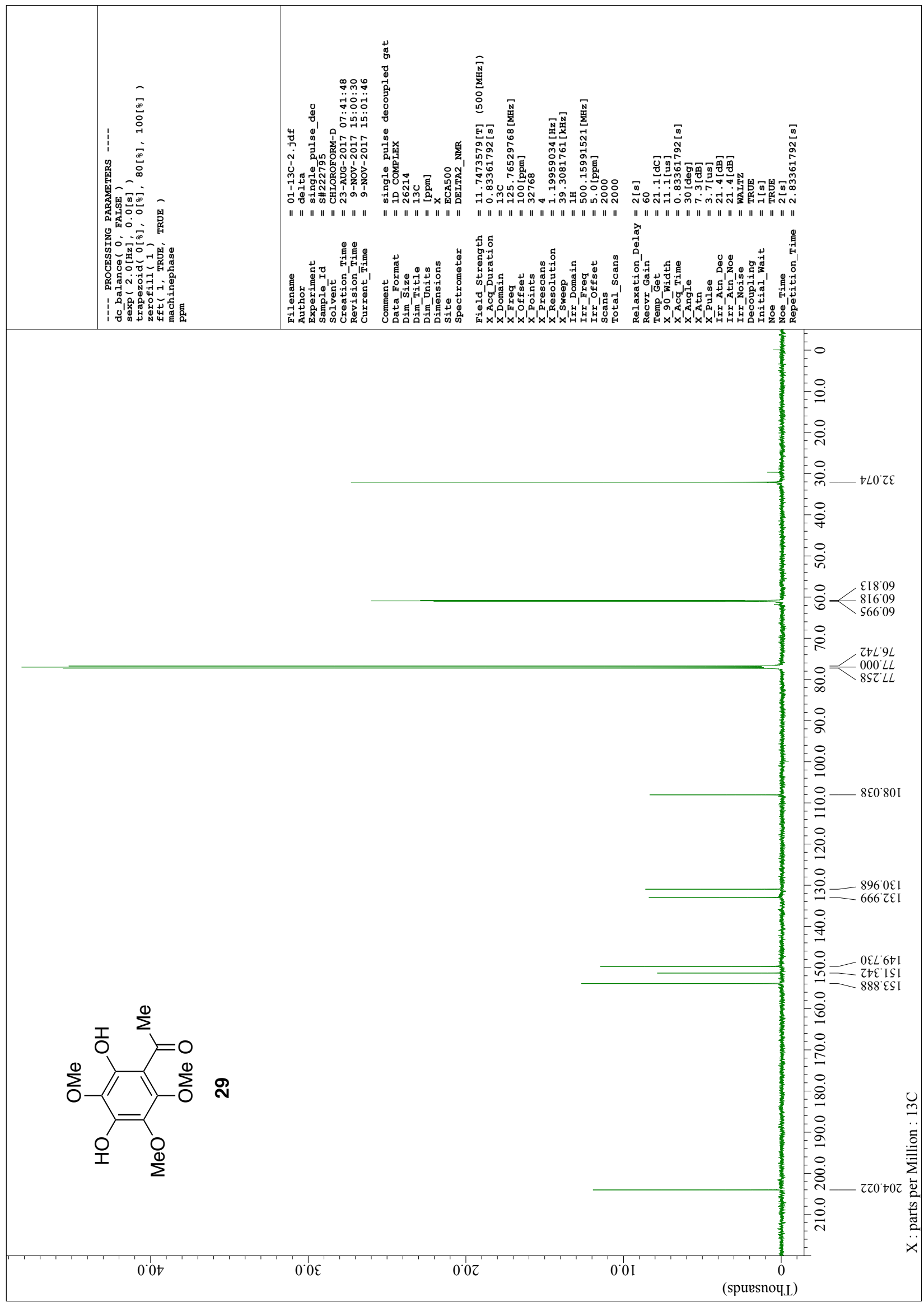




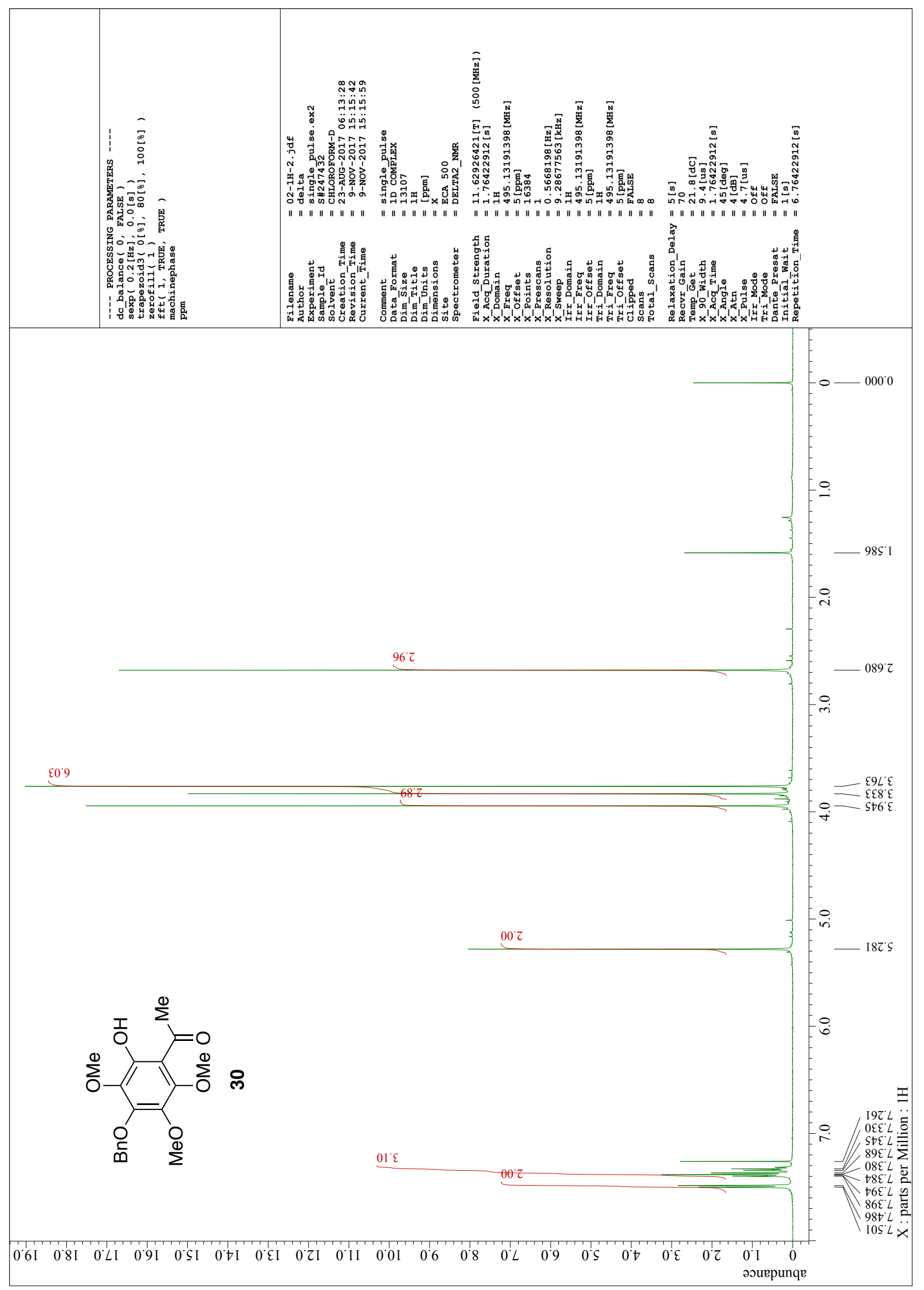




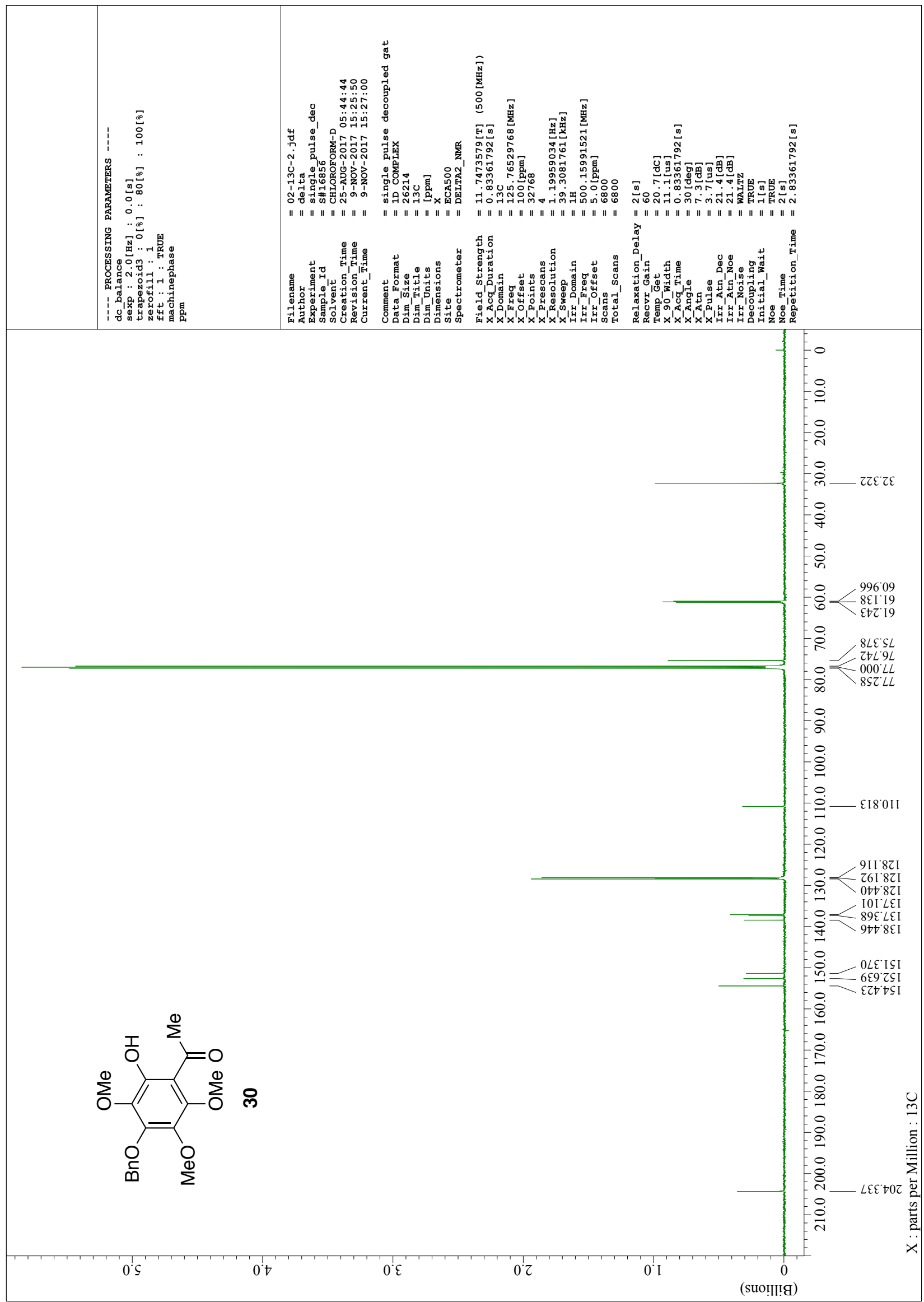




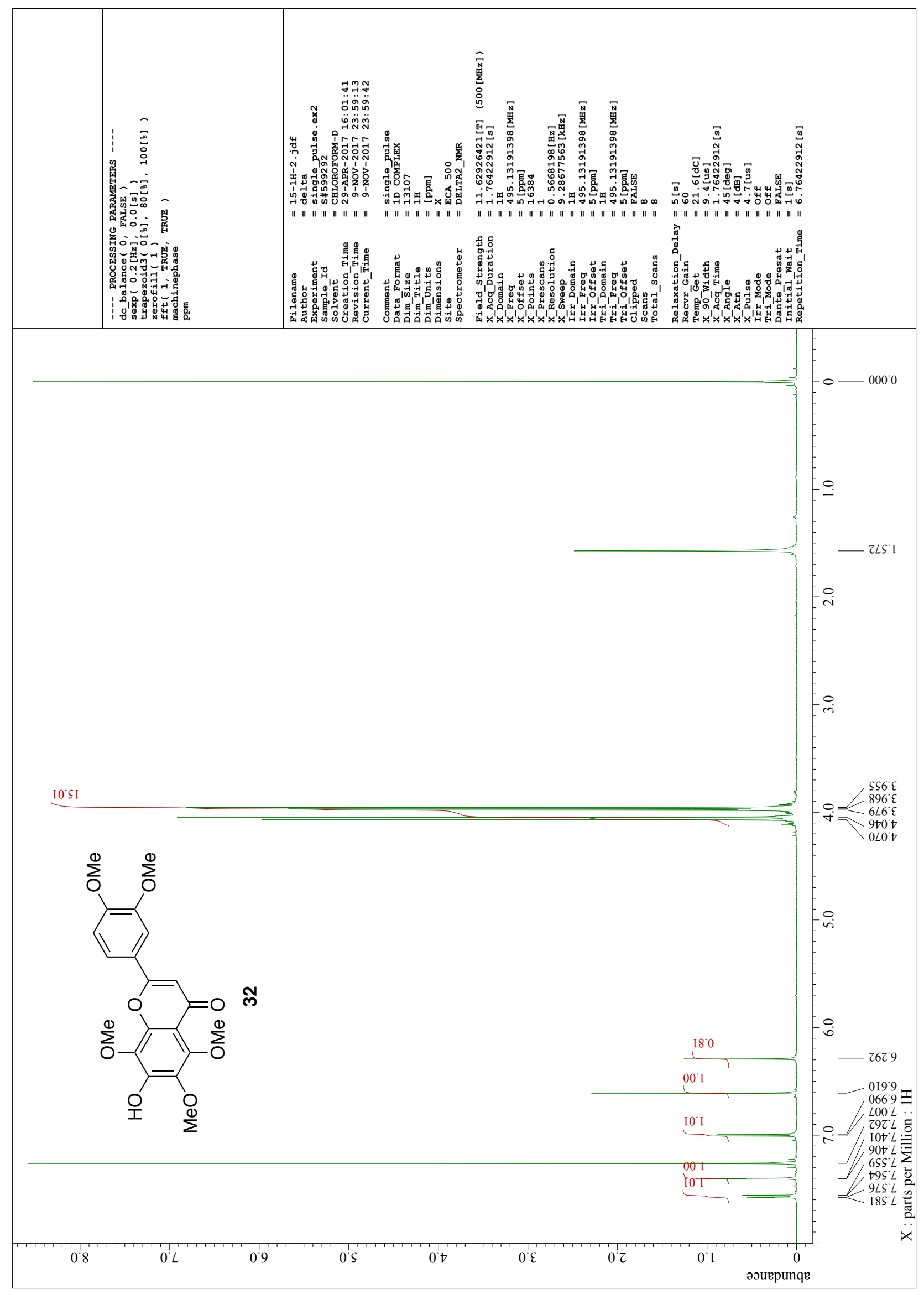

S21 


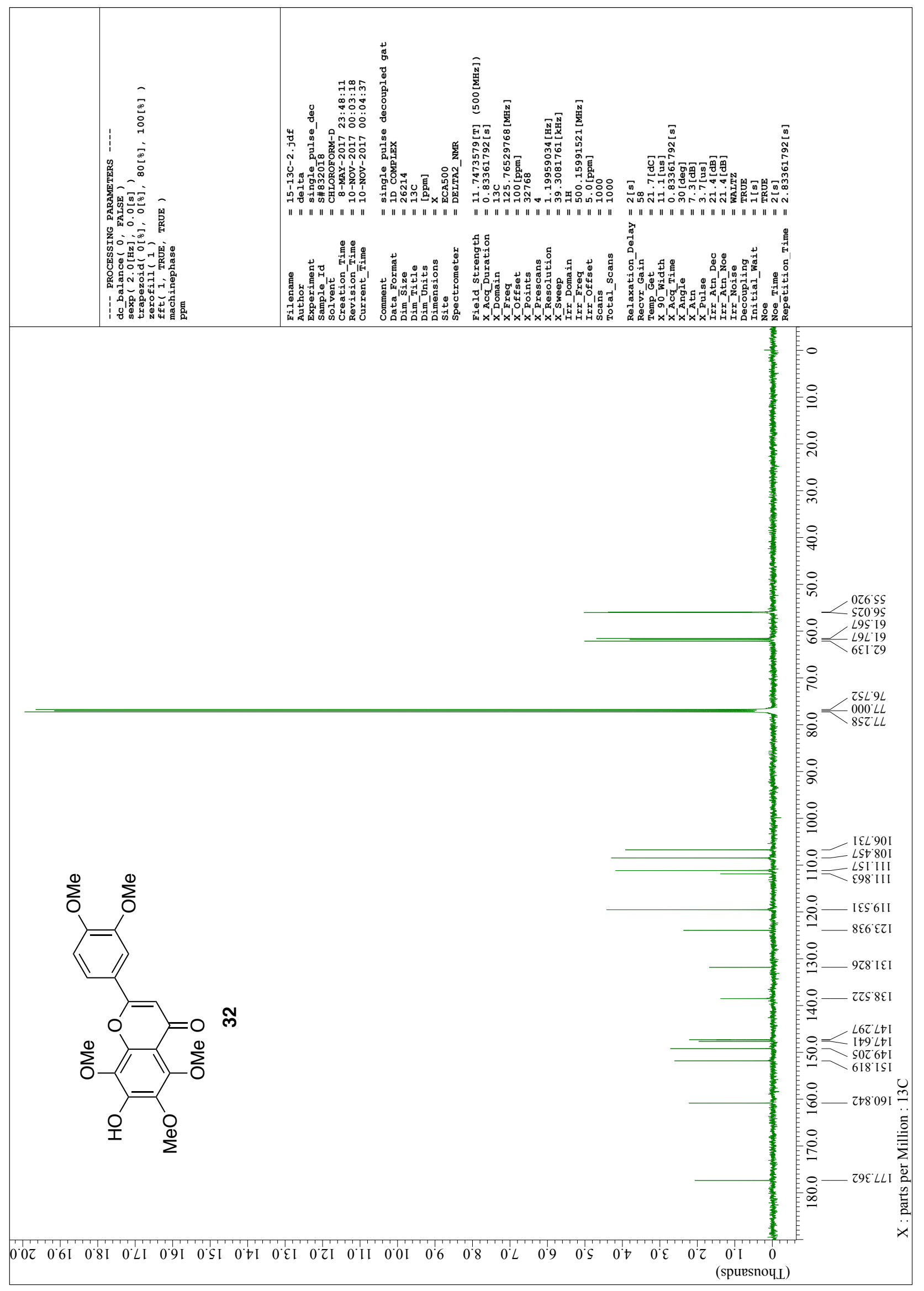




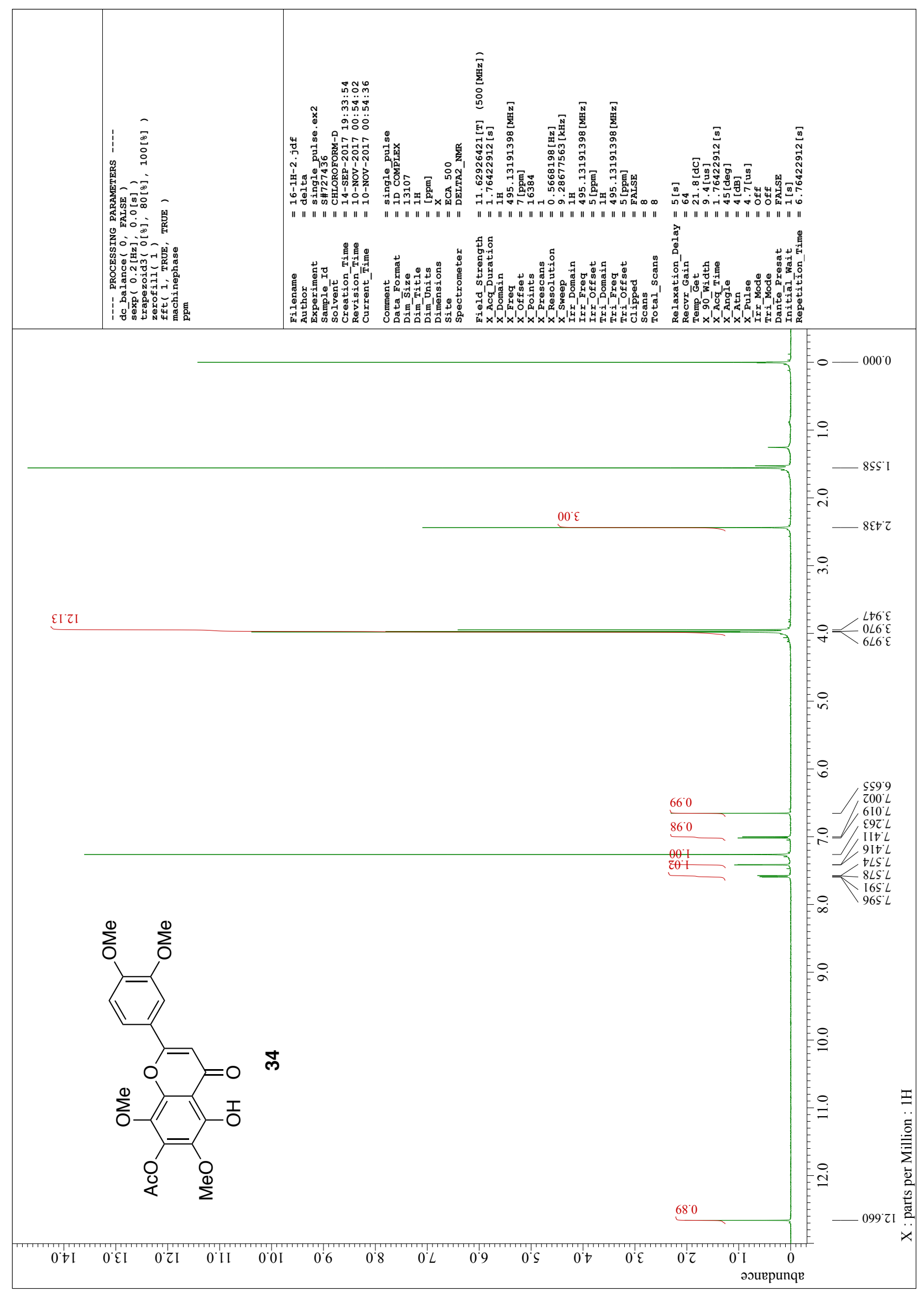

S23 


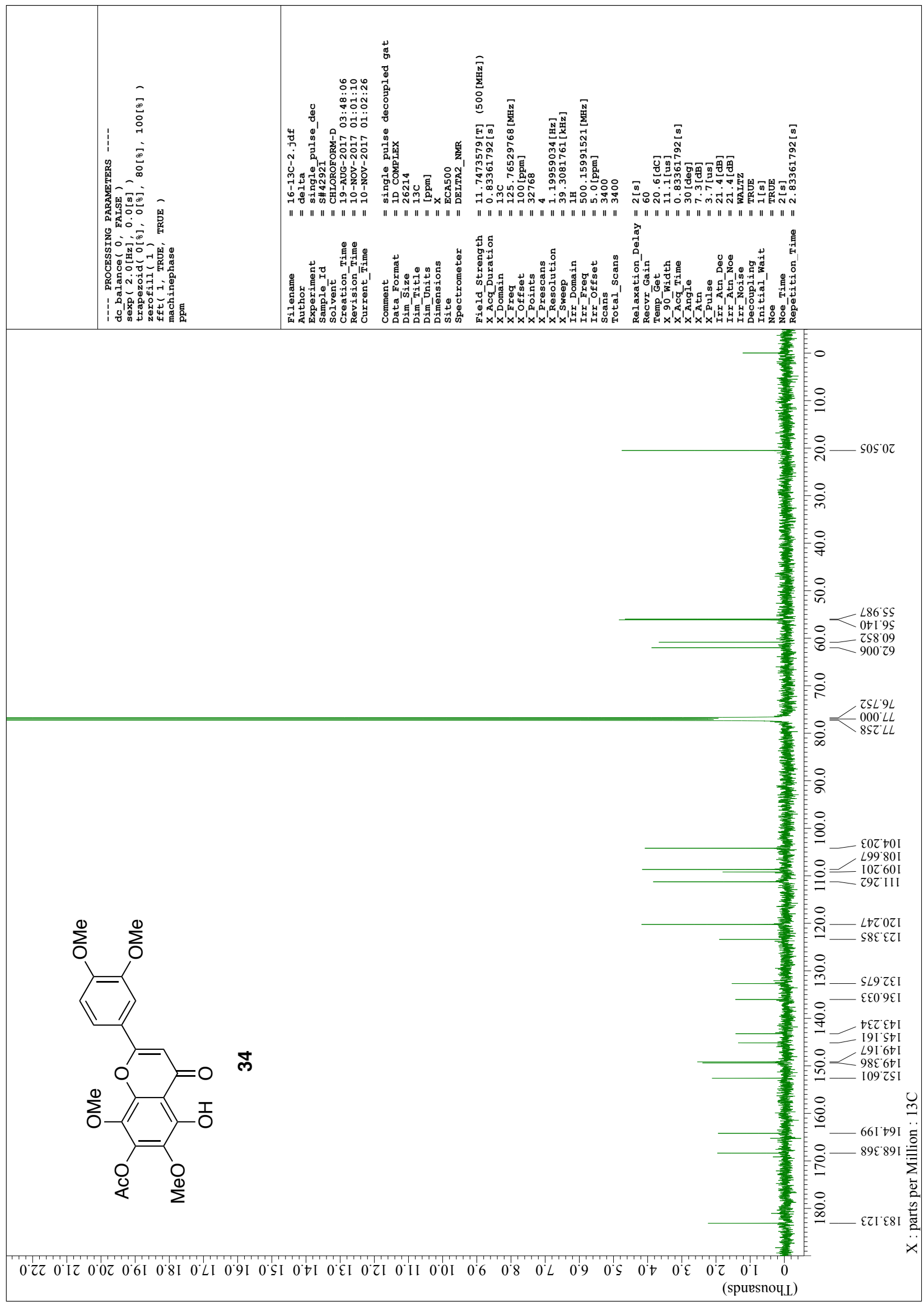




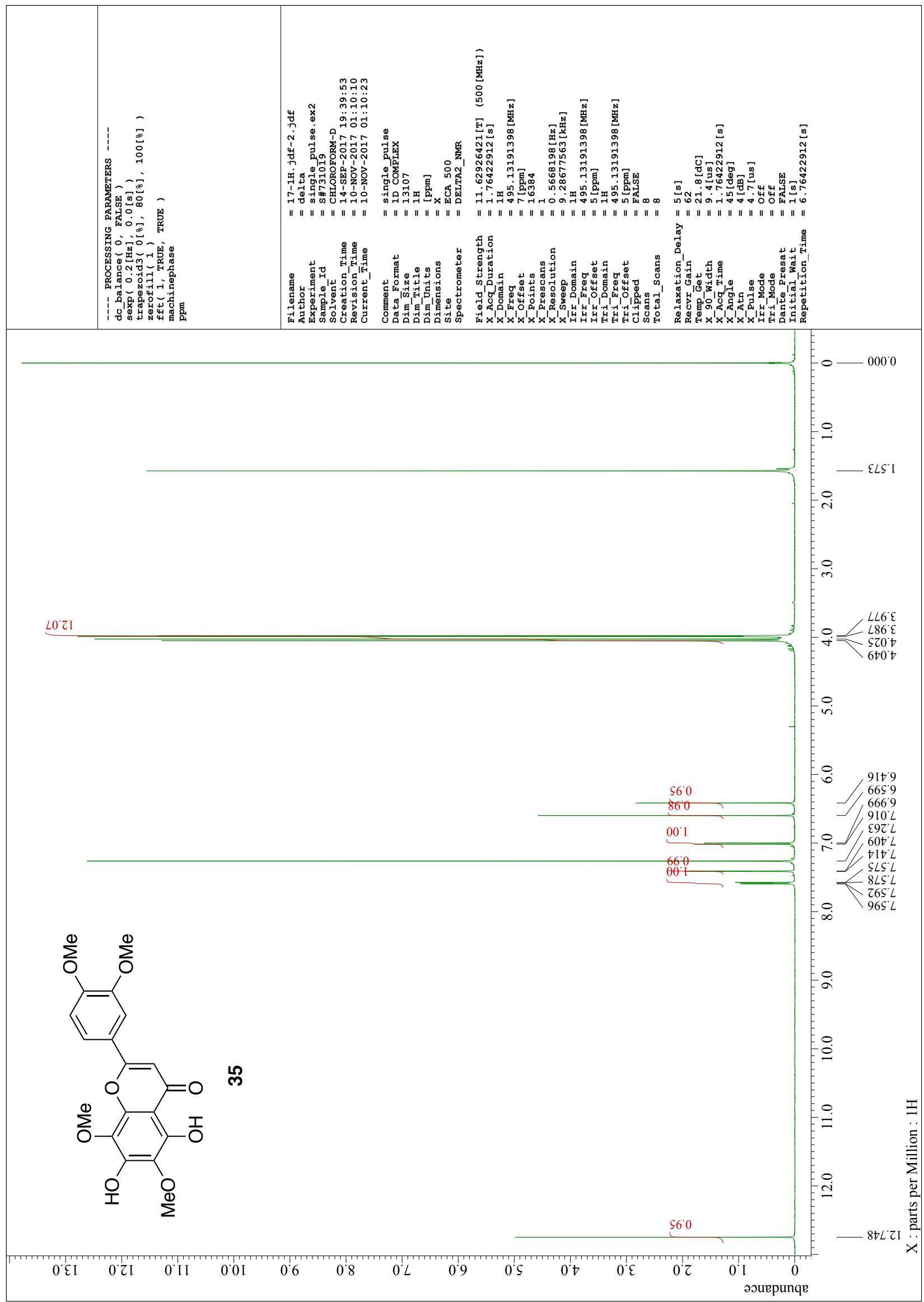




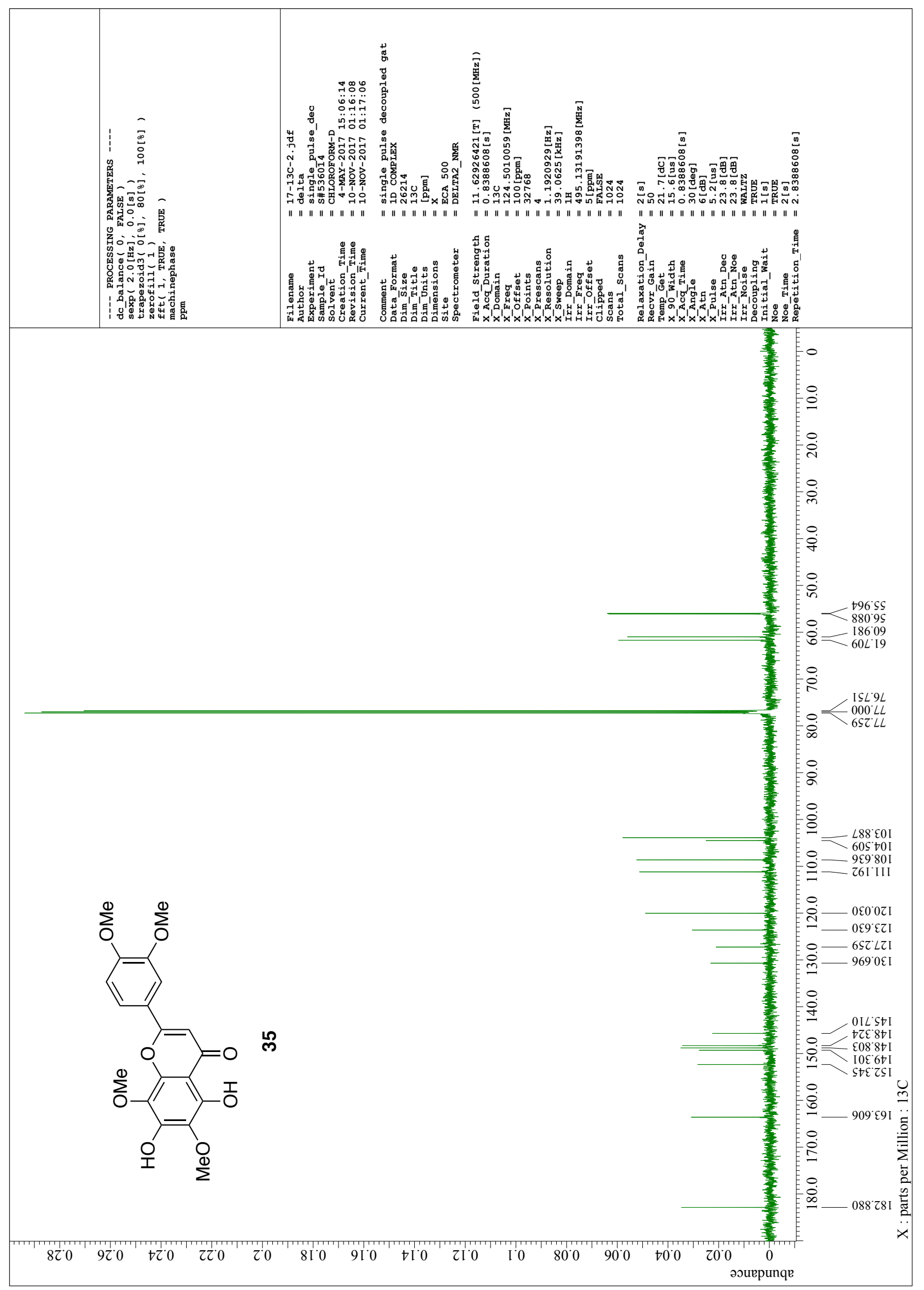

